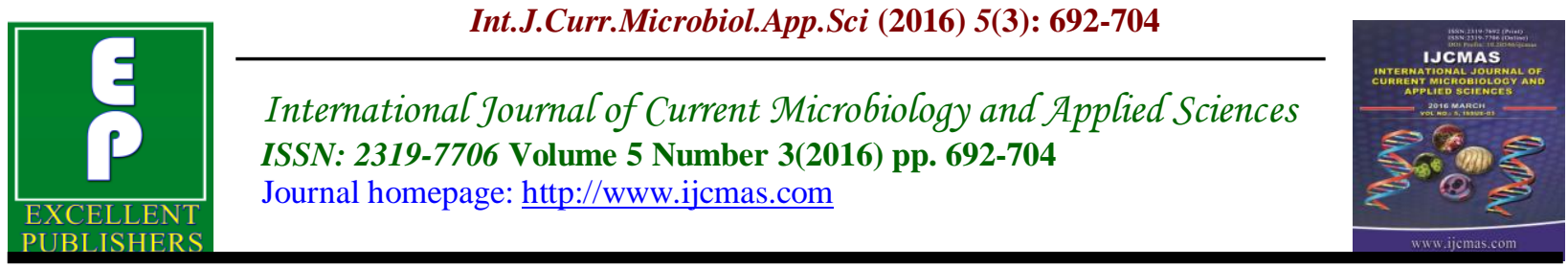

Original Research Article

http://dx.doi.org/10.20546/ijcmas.2016.503.082

\title{
Assessments of the Effect of Land use/ Land Cover Changes on Soil Properties in the North Eastern Nuba Mountains Region, Sudan
}

\author{
Elgubshawi A. Abdelmoneim. I. ${ }^{1}$, Doka M. A. Elabbas ${ }^{1}$, \\ Suliman Mahgoub ${ }^{2 *}$ and Franz Makechin ${ }^{3}$ \\ ${ }^{1}$ Soil and water Sciences Department, College of Agricultural Studies; Projects Management \\ Dept. CCF, Sudan University of Science and Technology, Sudan \\ ${ }^{2}$ Head Forestry Department, College of Forestry and Range Science, Sudan University of \\ Science and Technology, Sudan \\ ${ }^{3}$ Soil Institute, TUD, Germany \\ *Corresponding author e mail: aelgubshawi@hotmail.com
}

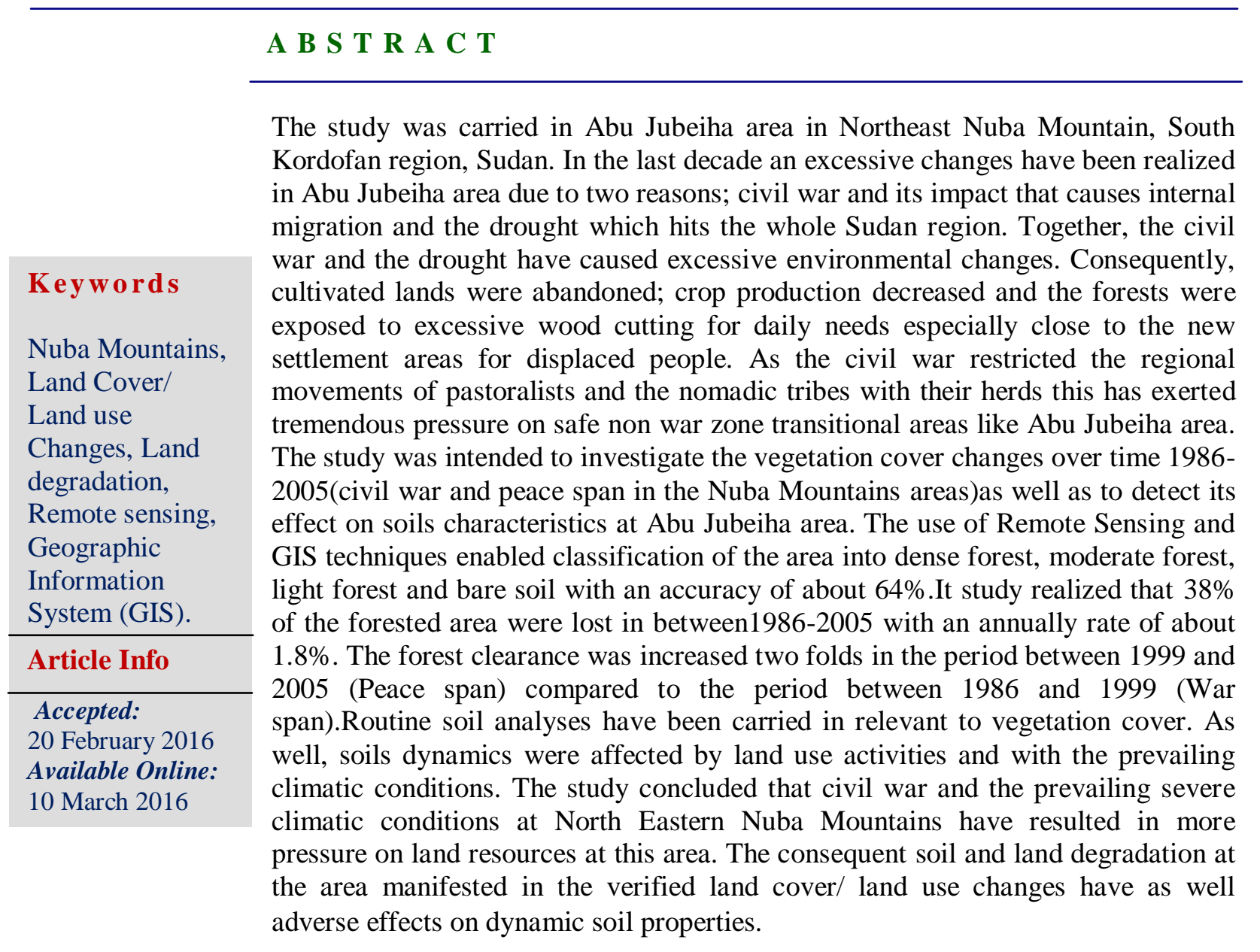




\section{Introduction}

The first serious sign of soil degradation in the Sudan was reported by Kennedy-Cooke (1944). The flat clay plains and sandy areas of the Sudan are continuing exposed to heavily overgrazing, over-cultivation, and cutting of trees for domestic purposes. Mechanized rain-fed agriculture and shifting cultivation have are increased from about 2. 0 million ha in 1954 to about 14 million ha in 1994, a rate of 300,000 ha per year(Tothill, 1954; Ministry of Environment and Tourism, 1996).Atta El Moula, (1985) reported that wild fires are consuming about $35 \%$ of the natural range productivity annually. While Salih (1996) revealed that the effect of opening five thousands and five hundreds (5500) boreholes wells in anti-thirst campaigns during the period 1960-1990, led to vegetation denudation and soil pul verization. In this regard, Ayoub (1997) reported that about 400 million Acacia trees being uprooted annually for rain-fed cropping,

Land degradation and desertification in Sudan have been assessed for several times within global and regional attempts. Although it was agreed that severe degrees of land degradation are caused by human factors but different estimate levels have been noticed. The highest estimations were stated by Dregne (1991) in comparison to UNEP (1977) and FAO/UNEP (1984). GLASOD soil degradation assessment shows that severe and very severe degradations make 58 million ha. Difference between assessments, according to Ayoub (1997) could be due to the different methods followed where some of which focused on vegetation degradation without significant soil degradation.

However, the Sudan experienced different types of soil degradation; the wind erosion in the hyperarid and arid zones of Kordofan and Darfur where the vegetation is poor and soil particles are loose. Topsoil loss through sheet erosion is a common type of water erosion in the semi-arid and arid zones and formation of gullies is an extreme form. The rich soils of the Nuba Mountains, Southern Kordofan are experiencing high topsoil loss; mainly caused by clearance of sloping terrain, the use of heavy machinery and mono-cropping.

The major cause of soil degradation beside the known traditional ones is the imbalance population in the Sudan since the majority live in arid and semi-arid zones (UNSCO 1997). Within national interest for a sustainable use of the natural resources, many on-going pilot projects scattered in southern Kordofan region to promote rainfed farming management practices to sustain and ensure land productivity. This has resulted in deterioration of productivity suggesting that scientific and technical knowledge of the agricultural environment, interactions between land components (soil, LU and LC) and their change over time is essential to promote productivity. The objective of this study is to understand dynamics of soil as affected by land use and land cover with quantitative data to assess the magnitude of soil loss/condition under different land use and land cover types.

The study area is part of vast undulating forested region, underlain by Precambrian Basement Complex, located in the East North Nuba mountains, South Kordofan State between $11^{\circ} 2308.79-10^{\circ} 5248.17 \mathrm{~N}$ and $30^{\circ} 0005.99-31^{\circ} 2804.91^{\prime}$ E, within the Universal Transverse Mercator projection (UTM) zone $36 \mathrm{~N}$, in semi-arid zone (Figure $1)$. The climate is characterized by a rainy season (July-October) and dry season. The average annual rainfall is between 500 to $850 \mathrm{~mm}$, with annual average temperature 
between $30^{\circ} \mathrm{C}$ and $35^{\circ} \mathrm{C}$.Maximum average monthly temperature of about $39^{\circ}$ occur in the three months preceding the wet season, minimum average monthly temperature vary between $17^{\circ} \mathrm{C}$ and $20^{\circ} \mathrm{C}$ and occur at highest of the dry season. The rrelative humidity is low (20-30\%) in the dry season and rises to about $80 \%$ in the wet season. Winds are generally moderate $(5-6 \mathrm{Km} / \mathrm{hr}$. $)$ and common throughout the year, (Van der Kevie,1973). The vegetation composition changes with rainfall from North to South. The most characteristic species are Acacias sp.; A.mellifera,A. seyal, A.senegal, A. compylacantha, A. fistula and A.drepanlobium. Ficus spp. are dominant On hill sides such as F.populifdia, F.glumosa with some other species like; Boswelliapa pyrifera, Combretum hartmannianum, Andropogen gayanus, Pennisetum pedicellatum and Hyphae nethebaica.The grasses are Aristida species, Elyonurus royleanus, and Sectariapallide-fusca.

\section{Materials and Methods}

\section{Materials}

Remote Sensing data comprise of multi sensor and multi temporal data. Satellite data include data from Landsat ETM and ASTER images. Multi temporal Landsat were acquired on $15^{\text {th }}$ November 1986 and $27^{\text {th }}$ November 1999and ASTER image ACQUIRED on $15^{\text {th }}$ Feb.2005.Digital Elevation Model (DEM) from GLCF online data, topographic maps (Sudan topographic sheets of Rashad, Melut and Talodi at scale 1:250000) and geological map of scale 1:1,000,000 (GRAS, 1986).

Soil map of North and South Kordofan at scale 1:250.000 (Pacheco and Dawoud, 1976) and semi detailed soil map of Eissa (1980) ,soil survey tools, digital camera, Germin 12 XL GPS and software such as
PCI geomatica. Matlap and Gamma Design were used. Three subsets of Aster image were prepared and then printed at 1:50,000 scale(False Color Composite) for navigation purposes. Four weeks of intensive field work carried to collect ground truth information and to characterize the soils and collect soil samples along the survey area.

\section{Methods}

\section{Images Analysis and Maps Producing}

Images(Aster) were Geo-rectified, converted to UTM and resized into $28.5 \mathrm{~m}$ resolution to match with the ETM image (1986, 1999). Atmospheric correction was applied to minimize the effect of atmospheric conditions difference between images.

\section{Data Transformation}

Bands selection and reduction techniques have been done according to developed (Bosch and Rand 2002). Correlated bands transformed into a number of uncorrelated components and then the Principal Component Analysis (PCA) was applied to produce more colorful color composite images to speed up visual analysis and classification of the multispectral image (Jensen, (1996) and RSI, (2004)).

\section{Image Classification}

Unsupervised classification was carried and training areas representative of each land cover type were collected during 2005. Groups of pixels were selected from the area of known cover types. Areas of mixed land cover were not considered in order to avoid overlaps in training samples. The Maximum likelihood algorithm was used using PCI geomatica 10. The algorithm considers the spectral variability within each category and 
the overlap that may occur among different classes (Campbell, 2002).

\section{Classification Accuracy Assessment}

A set of random reference pixels were used. Overall accuracy and overall Kappa statistics were measured (Congalton, 1991,Kerleet. al. 2004). The overall accuracy is weighted by the number of samples/pixels in each class. The relation of the test sample data was summarized in an error/ confusion matrix.

\section{Land Cover Change Detection}

The method of using wavelengths to compare multi-data was applied (Skidmore, 2002). To detect the change between the two data sets the simplest approach of Huang et. al. (1998) was used. Data were classified and labeled independently to get advantage of compensating for varied atmospheric and phonological condition between dates of even.

\section{Soil Characterization}

The study area is subdivided on physiographic basis into three landscape ecological zones (Figure 2); according to altitude and soil drainage: zone AA represent the undulating physiographic system, zone $\mathrm{BB}$ and zone $\mathrm{CC}$ were taken along the slope to represent the down and upper slope respectively. The soil at field level were grouped into two major soil types Clay (gray to black) and Gardud soils (Brown to reddish brown) based on soil particle size distribution and their colours. Sub-major soil types Gravely Clay, Gravely Gardud, Red Gardud and Stony to Gravely soil were characterized. The vegetation cover types (Dense, Medium, light, Fallow and Bares soil) are considered for each soil type.
Collected samples subjected to routine soil data analyses include; Laboratory preparation, Particle-Size Analysis by Sedimentation (Pipette method with an automatic particle size analyzer ), Analysis of Total Carbon and Total Nitrogen. ( a tin capsule solid sample is placed under a helium stream in an oven at $850^{\circ} \mathrm{C}$. Injection of oxygen causes a very brief rise in temperature $\left(1800^{\circ} \mathrm{C}\right)$ and total combustion. The respective $\mathrm{C}$ and $\mathrm{N}$ contents are measured by gas chromatography), Determination of Carbonate Content in Soils (Volumetric method),. Analysis of the Cation Exchange Capacity (CEC) (by the hexaaminecobalt trichloride method using ICP spectrometry), $\mathrm{pH}$ (Measurement is performed with a combined glass electrode in a 1:2.5 (M/V) soil suspension), Measurement of the Electrical Conductivity of a Solution (Measurements are performed using a conductivity meter with direct reading on the scale selected. The apparatus is calibrated using a $56 \mathrm{mg} / \mathrm{l} \mathrm{KCl}$ solution whose conductivity is $100 \mu \mathrm{S} / \mathrm{cm}$ at $25^{\circ} \mathrm{C}$.

The study covered a total area of about 250,000 ha. Representative soil samples (105) and soil profiles were described using the FAO guidelines for soil description (FAO, 1990), and sampled by genetic horizon. Each sample was a bulked composite of three sub-samples taken with auger in diagonal basis. Subjectively the samples were collected to represent both soil type and land cover. The geographic coordinates of each sampling point were recorded using the Global Positioning Systems (GPS).The elevation of each sampling point was recorded from a georeferenced-interpolated contour map of the area (scale 1:250 000). All the soil samples were analyzed in the Soil laboratories at Institute of Soil Science and Site Ecology, TU Dresden using procedures of soil 
analysis described in DIN Deutsche Insititüt für Normung e.v.

\section{Results and Discussion}

\section{Land Cover Mapping}

The result (Figure 3) has indicated that; cultivated area (Bare and Fallow) is the biggest followed by Light Forest (LF) land and Dense Forest (DF) land use/covers. Medium Forest (MF) is only covered $6 \%$ of the study area.

\section{Accuracy Assessment}

Accuracy assessment showed that the overall accuracy is about $64.54 \%$ and the kappa coefficient is 0.63 . The Kappa value indicates that the accuracy of the supervised image classification using Maximum Likelihood Classification is $63 \%$ better than doing it randomly or using unsupervised method. The overall accuracy obtained is relatively better compared to Pereira (2004) findings in Mozambique (about 53\%) for eight land use/covers using ASTER imagery. Marcal et al. (2005) found classification accuracies ranging from $44.6 \%$ to $72.2 \%$ using different classifiers of ASTER data in Portugal. While accuracy reported by Aynekulu et.al( 2008 ),in Ethiopia reached $80 \%$. No sensitivity analyses was done for the accuracy and it was assumed that the ground truth for the different land use/covers is absolutely correct as stated by Mann and Rothely,(2006). Generally, the classification accuracy found in this study is looked acceptable to map land cover as a base for monitoring and management in the study area where data is scare, with focusing on other classification techniques. Relatively low classification accuracy in this study might be due to difficulties of having no distinct delineation between classes.
Approaches of classification depending on vegetation species might introduce a better classification accuracy as well as using more than on techniques will support the accuracy result.

As indicated in Table 1, the medium forest classes (MF) were classified with higher use $(75 \%)$ and produces $(75 \%)$ accuracies. This is might be due to the characteristics of Ficus species, which were relatively broad leaves types in regard to the rest Acacia spp. In other hand there is some spectral signature overlap among the cultivated, LF and DF lands. The mixture is partly due to the open canopies of the shrub and grasses. Moreover, the dominate tree species that covers large parts of the study site is Acacia species that have tiny leaves which might not give clear spectral signature for ASTER optical sensors. The spectral signature of the cultivated lands is also mixed mainly with grass of Fallow land (FF).

\section{Land Use/Cover Status: Soil Adjusted Vegetation Index (SAVI)}

Figure (4) shows change and no change happened with the time span from 1986 to1999 and from 1999 to 2005 . The result deduced that, late 5 year span from 1999 to 2005 experienced drastic land use/ cover changes. Dark colour means highly affected spots. Changes taken place in the Northeast the study area are noticeable. The Soil Adjusted Vegetation Index (SAVI) was implemented as a best model to identify land use and cover in relative dry grass land. The visual differences of the land use/ cover were clearly depicted in (Figure 5). Vegetation covers showed severe fragmentation in 2005 image in compare to image 1999 and image 1986 respectively, indicating serious vegetation degradation with time as well as human pressure. More than 87,000 ha were lost in the last two 
decades with average loss of about $1.8 \%$ per year. The result is strong sign to the environmental degradation that taking place in the study area and in the Sudan as well, particularly the soil erosion that would be enhanced at vegetation loss (Hill et al 1995a). Atta El Moula, (1985) and UNEP report, (2007) declared that Sudan's deforestation rate of natural forests was closed to $2 \%$ per year which has been emphasized by this study $1.8 \%$.

\section{Land Covers Changes Detection}

The land covers changes were then detected as it shown in (figure 6a,b).

The cultivated land $(\mathrm{BF}+\mathrm{FF})$ was proliferated three times in the last two decades. It was increased from $10 \%$ in 1986 to $20 \%$ in 1999 and to $40 \%$ in 2005 . In other words the change that happened in the last
5 years is equal two times the changes in previous 15years. The non- cultivated (DF, $\mathrm{MF}$ and LF) or forest land was reduced by $38 \%$, from $79 \%$ in 1999 to $49 \%$ in 2005 .

\section{Soil Dynamic Response to Land use/cover}

The soil dynamic response to LU/LC was measured in reference to virgin soil under the Dense Forest in both clayey and Gardud soils. The results (Figures 7a,b)revealed that, there was a considerable variation between soil variables and between soils as well.

The soil physical parameters were affected considerably when compared to the chemical ones. As well as the Red soils (Gardud soils) were relatively more affected than the Dark clayey soils. Gardud soils are vulnerable to rain drops detachment and transportation as stated by (Elgubshawi,1995).

Table.1 Accuracy Assessment (Confusion Matrix)

\begin{tabular}{|c|c|c|c|c|c|c|}
\hline \multicolumn{7}{|c|}{ Reference data } \\
\hline Classified data & DF & MF & LF & FF & $\mathrm{BF}$ & User's accuracy \\
\hline $\mathrm{DF}$ & 66.71 & 0.53 & 8.34 & 8.95 & 12.86 & 43 \\
\hline MF & 3.49 & 56.87 & 21.81 & 0.55 & 13.84 & 75 \\
\hline LF & 17.99 & 13.65 & 48 & 5.81 & 13.73 & 40 \\
\hline FF & 6.14 & 0.56 & 0.73 & 84.68 & 6.6 & 60 \\
\hline $\mathrm{BF}$ & 13.97 & 11.41 & 8.69 & 12.33 & 52.31 & 50 \\
\hline Producer's accuracy & 60 & 75 & 50 & 50 & 40 & \\
\hline
\end{tabular}


Fig.1 The Study Area Location and Elevation Characteristics

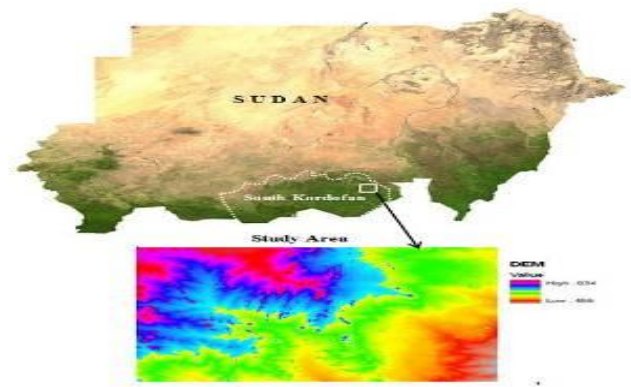

Figure.2 Physiographic Map Showing Location of (Aa, Bb And Cc) Areas and Samples Spatial Distribution Pattern

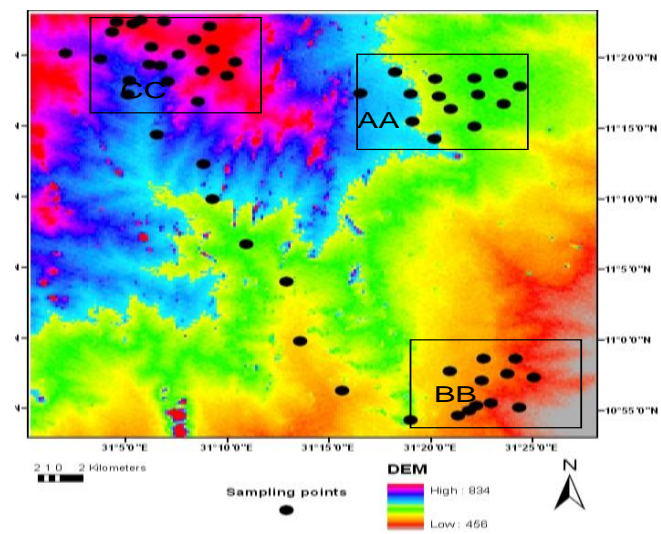

Figure.3 Show Land Cover Types and their Percentage
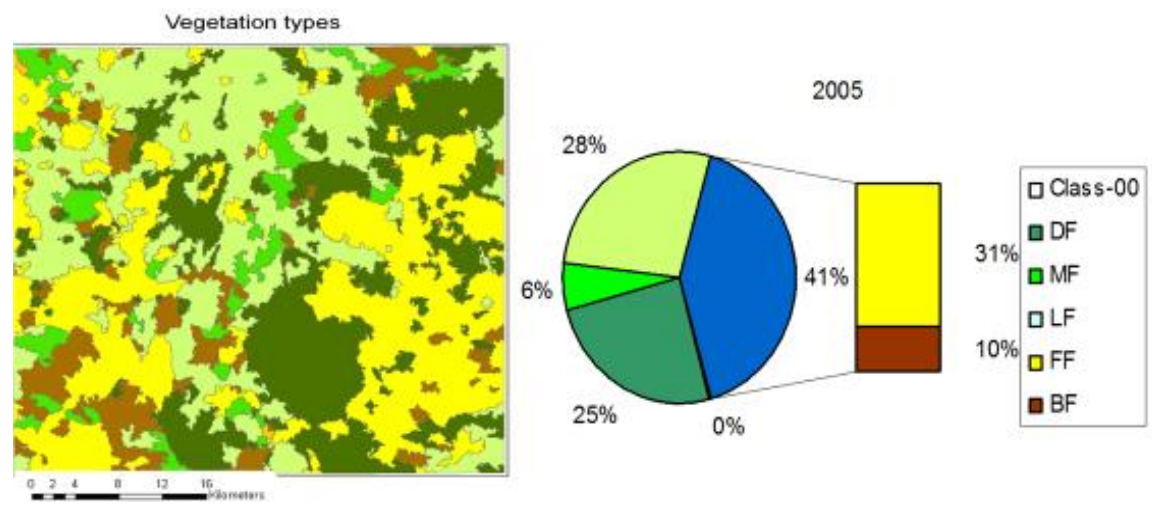
Figure.4 Changed and No Changed within the Study Site
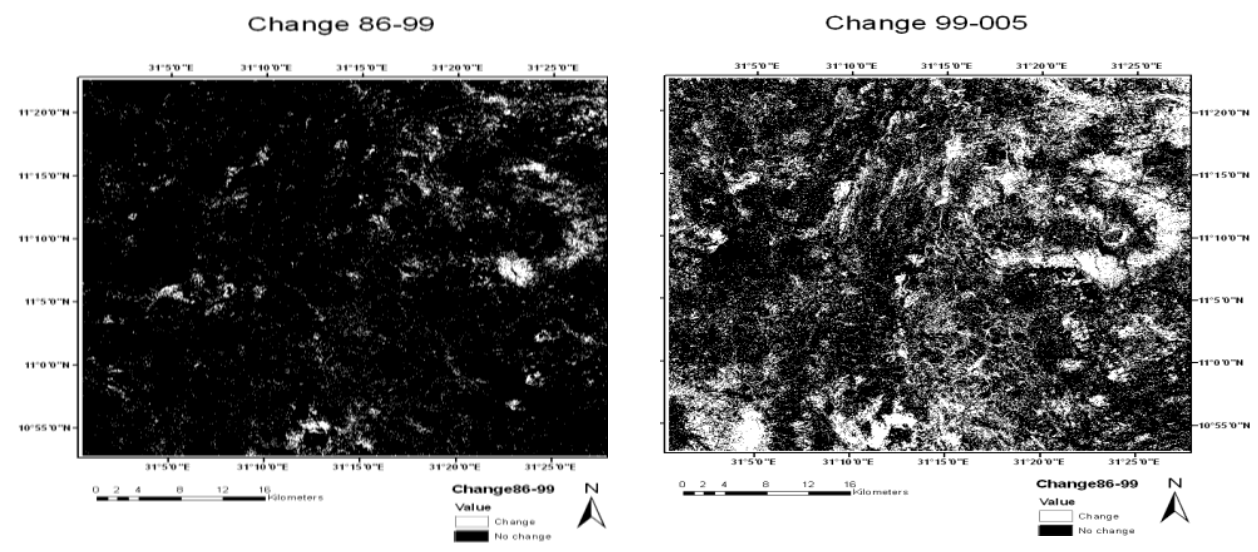

Figure.5 Land use/ Cover Detection using SAVI
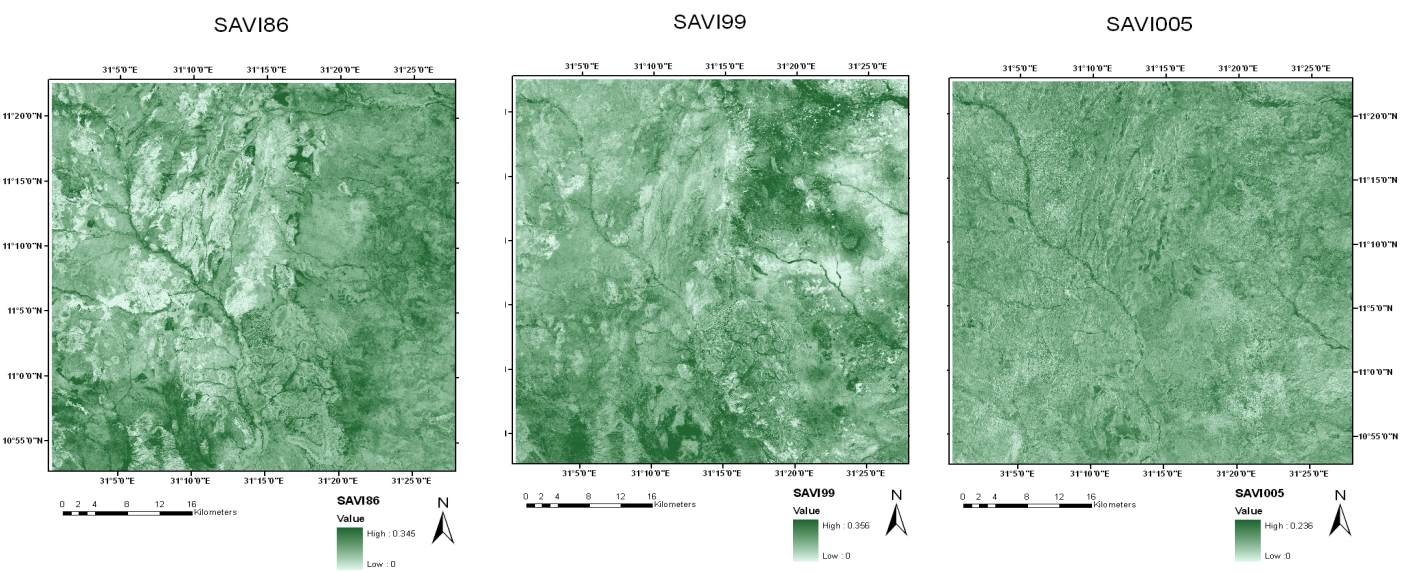

Figure.6a Land Use/ Land Cover
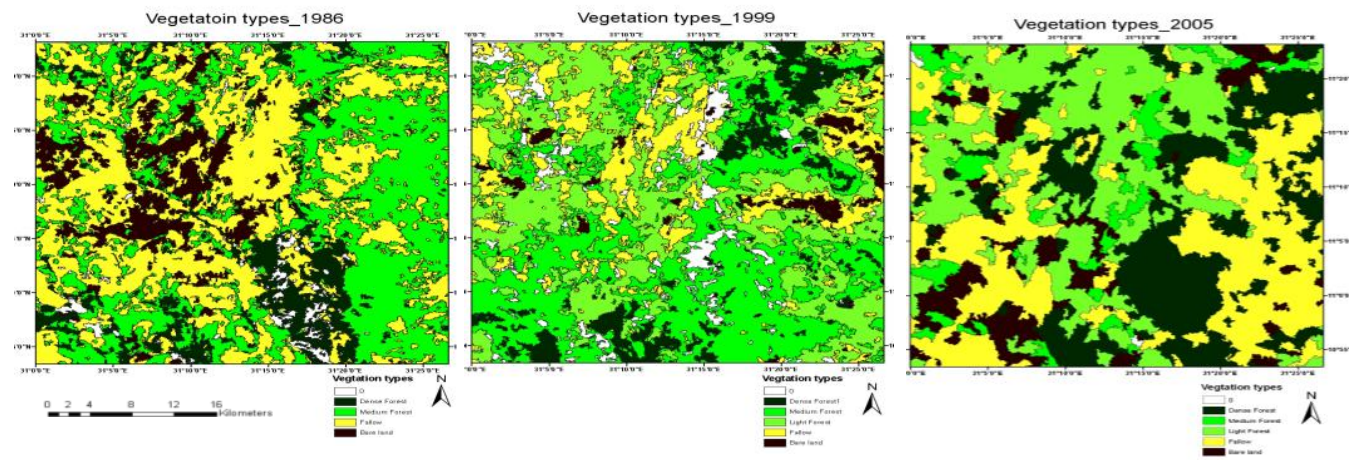
Figure.6b Land Use/ Cover Types and \%

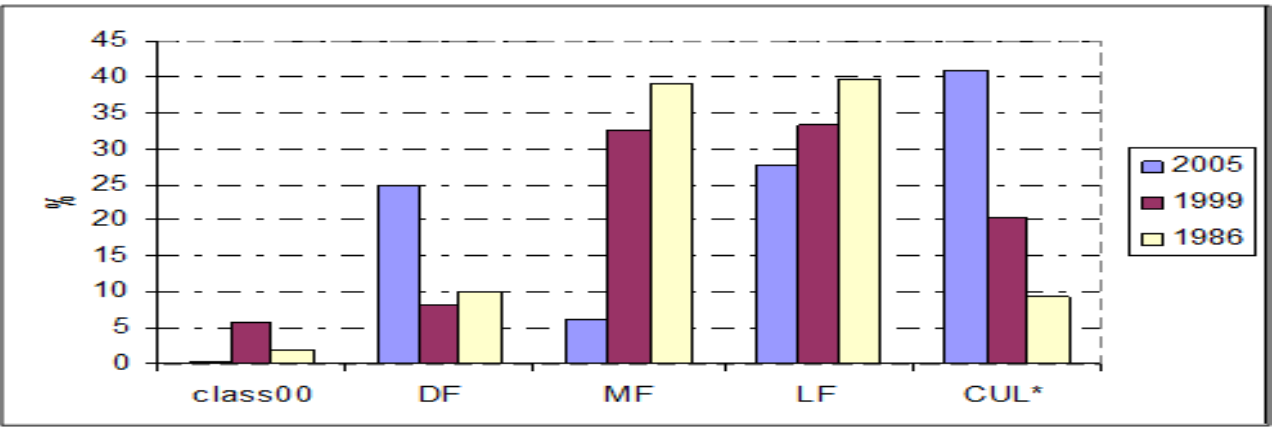

$\mathrm{CUL}^{*}=$ cultivated land $(\mathrm{BF}+\mathrm{FF})$. Class $00=$ land without land cover

Figure.7a,b Soil Properties of Two Soil Types at Different Vegetation Cover
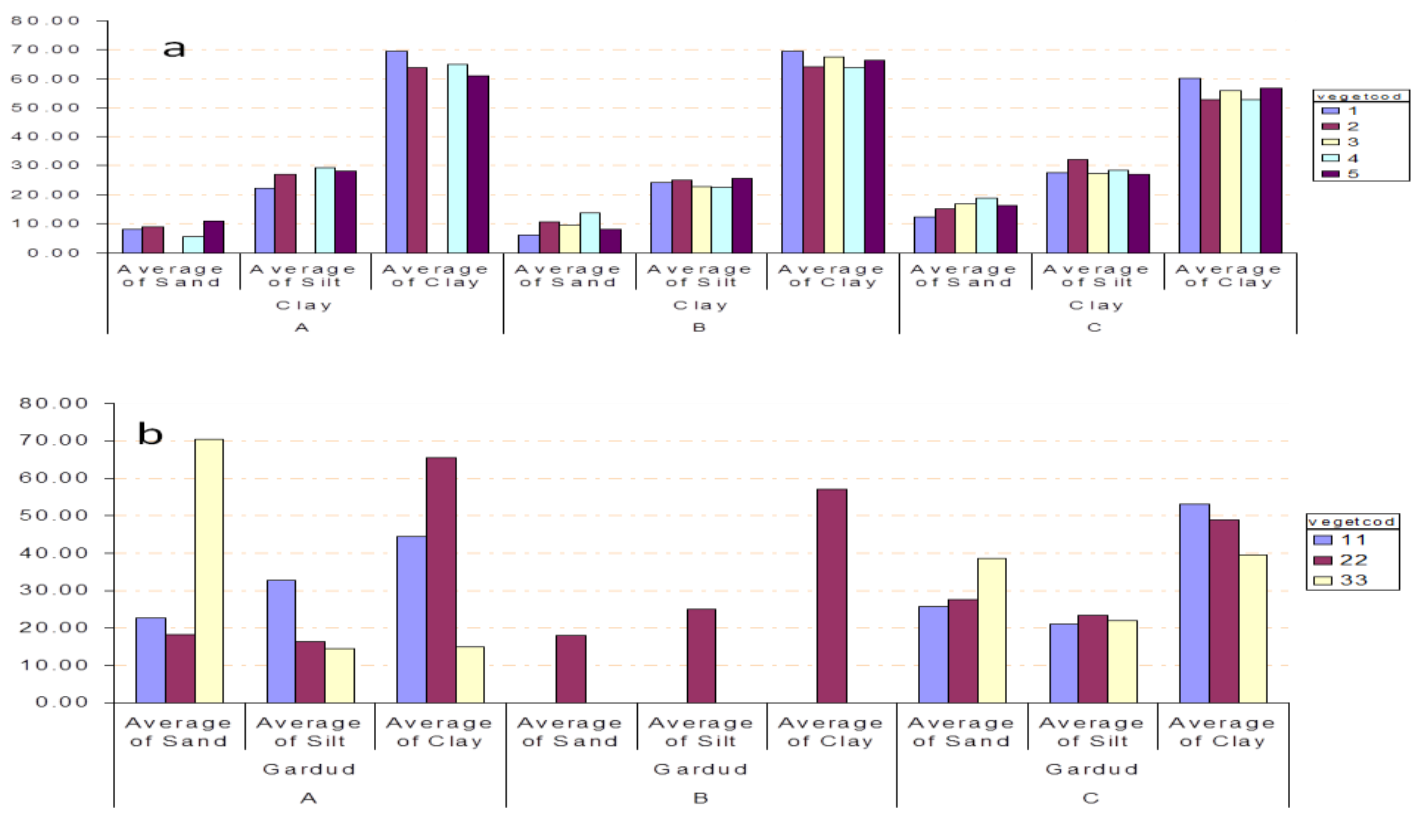

Figure.8a,b,c,d,e and $\mathbf{f}$ Soil Parameters as Affected by Soil Type, Vegetation Cover and Position

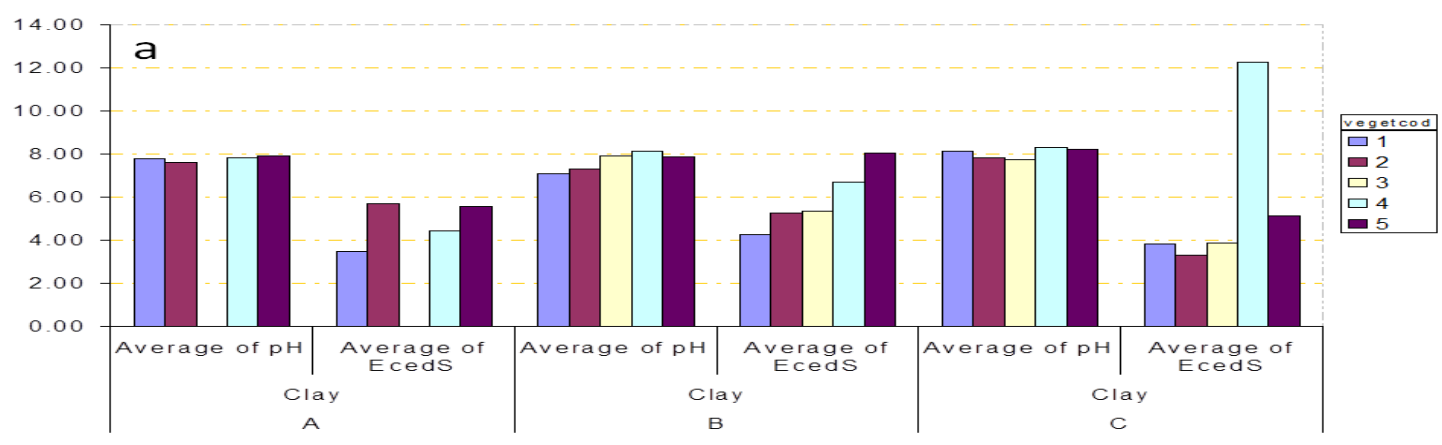



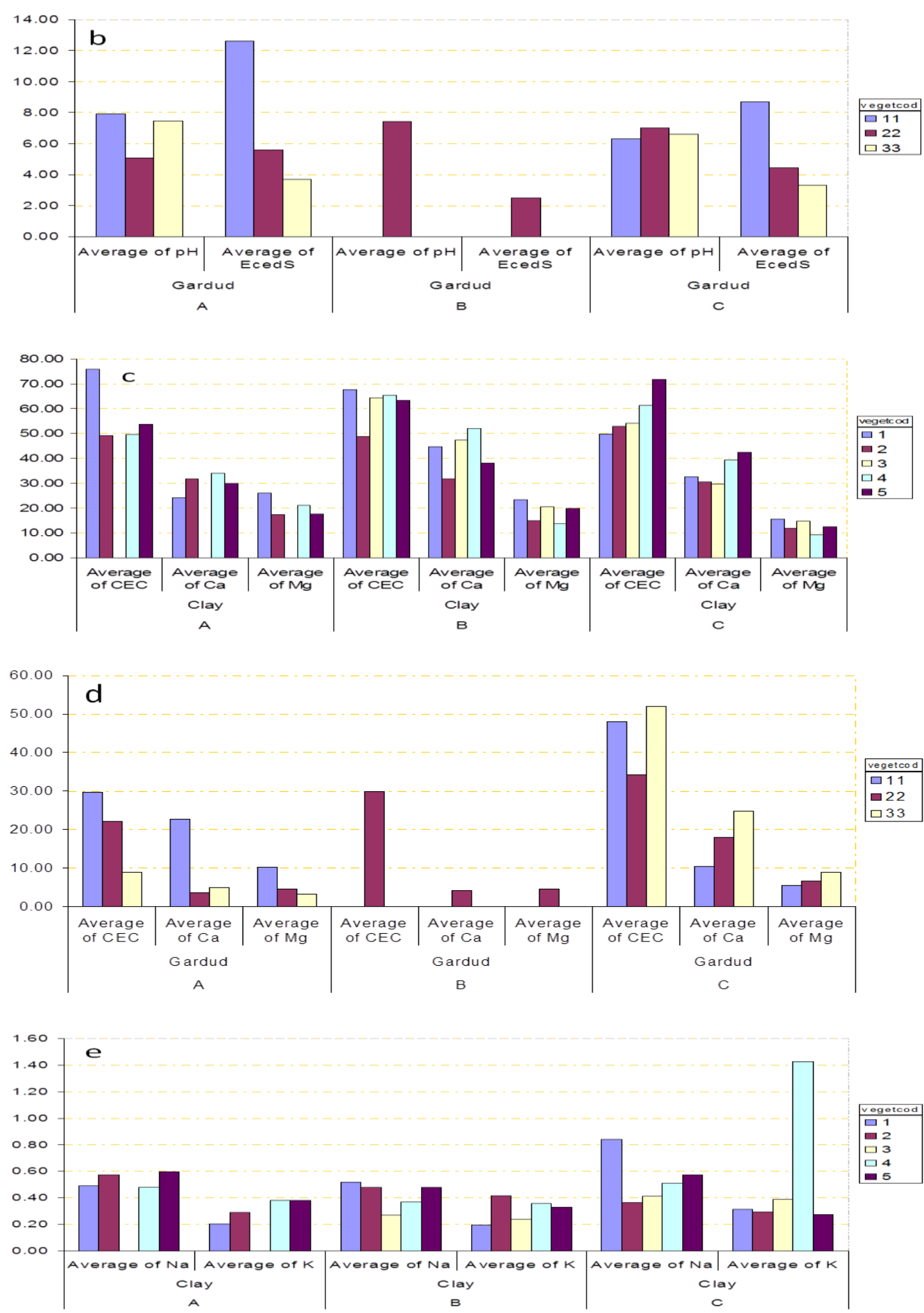


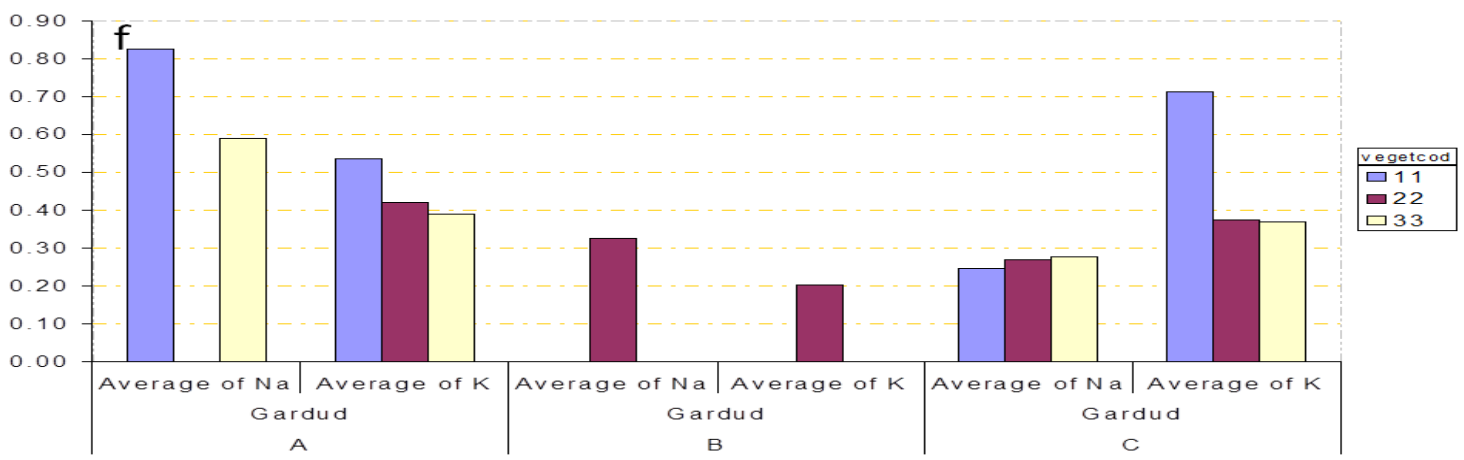

*1/ 11=Dense forest $(\mathrm{DF}) ; 2 / 22=$ medium forest $(\mathrm{MF}) ; 3 / 33=$ light forest $(\mathrm{LF}) ; 4=$ fallow $(\mathrm{FF})$ and $5=$ bare (cultivated) soil (BF).

**A= undulating, $\mathrm{B}=$ down slope and $\mathrm{C}=$ upper slope positions

The soil structure and texture in both the Red soils (Gardud) and the Dark clayey soils were affected positively with vegetation cover. Top soil structure of Light forest (L.F) as exposed to long term of grazing and as nomads temporary settlement have been differed when compared to virgin soil under the Dense Forest (DF).The texture results were emphasized that the top soil of the Light Forest was prone to loss of fine grains, most properly due to soil erosion.

Deterioration of soil structure is overriding and more general form of soil physical deterioration that necessitates the importance of taking any changes in the soil structure very seriously. High degree of interaction between the different physical, biological and chemical factors and processes involved might hide soil physical degradation. Salinity (EC), Cation Exchange Capacity (CEC), Exchangeable basis, TN, and $\mathrm{OC}$ were revealed different levels of dynamic (Fig.8a,b,c,d,e and f).The Gardud soils have low fertility level;Salinity, Exchangeable basis( $\mathrm{Ca}, \mathrm{Mg}, \mathrm{K}, \mathrm{Na}), \mathrm{TN}$ and OC were decreased at the LF soil deducing the prone of these soils to erosion process. The Dark clayey soils (Vertisols) are deep (2-6m), fertile and less depleted. These soils are totaling 12 million ha out of 70 million ha of vertisoils soils of the Sudan. According to Ayoub (2001) .The Dark clayey soils in south Kordofan were existed in situ of basaltic parent materials, belong to two soil series, Elbardab ( Grayish brown) and Dameik (Dark grayish brown) as stated by Eissa (1980).

The findings agreed with Ayoub (2001) and Eissa (1980). These soils are chemically rich, nevertheless they recorded a little bit less values for the CEC (49-54), a little pit high O.M (0.5-1.5\%), and non-saline soil. The TN\% is very low at all findings. The difference between results most properly attributed to the methods used. At a time that the result indicating no or subtle variation between the soils under different land use systems, the appreciable presence of gravel on the surface of these soils stand as an evidence of water erosion. But soil depletion or soil changes may have been hidden by the profile thickness and relatively high fertility levels. I am afraid to discover these facts at died time where resilience become too late.

In conclsion, in South Kordofan area civil war started at rich savannah areas which are usually the settlement areas for the nomads and pastoralists moving from the north during summer. Due to war these movements are restricted and pastoralists are obstructed at poor savannah areas at the northern parts of South Kordofan including 
the study area. As well, the displaced rural population (villagers) at war zone are bound to move to safe haven areas at the north. These entire exoduses end up at $\mathrm{Abu}$ Jubeiha area and some other few areas in northern parts of South Kordofan. These large settlements of population with their livestock create tremendous pressure on the already fragile environmental resources at Abu Jubeiha area.

Evident signs of environmental degradation are taking place in the study area. Serious vegetation degradation was documented. Vegetation loss average is about $1.8 \%$ per year. Palatable grasses were replaced by less palatable plant species and a considerable variable decrease in tree density was also noticed.

Soils are chemically rich and are non-saline. Evidence of water erosion is noticed. Depletion or soil changes may have been hidden by the profile thickness and relatively high fertility levels.

\section{Recommendation}

1. Widespread and rapidly accelerating environmental degradation is urgently needed to be addressed. It's one of the most driving forces of local civil wars in great Kordofan and elsewhere in the country that resulted in displacement of rural population, nomads and their animals. According to the Sudanpostconflict environmental assessment report, there are five million internally displaced people and refugees in Sudan.

2. Investment in environmental management financed by the international community and from the country's emerging boom in oil, minerals and gas exports will be a vital part of the building efforts that sustain the environment, natural resources and peace.

3. More research is required to locate degraded areas and identify degradation processes.

4. Remote sensing/ GIS techniques should be introduced in change detection applications and since their advantages and usefulness were proved in land degradation studies.

5. Rural development and rangeland management program should be initiated in degraded areas.

\section{References}

Atta El Moula, M.E.,1985. On the Problem of Resource Management in the Sudan. Environmental Monograph Series No. 4. Sudan: Institute of Environmental Studies, University of Khartoum. $131 \mathrm{pp}$.

Aynekulu E., Kassawmar, T. and Tamene, L.2008.Applicability of ASTER imagery in mapping land cover as basis for biodiversity studies in drylands of northern Ethiopia. African Journal of Ecology 46(s1),19-23

Ayoub, A.T. 2001. Vertisols Management in the Sudan. The Sustainable Management of Vertisols, eds. Syers, J.K., Penning de Vries, F. and Nyamudeza, P. Hardback.CABI.101-111pp

Ayoub, A.T.1998. Extent, Severity and Causative Factors of Land Degradation in the Sudan.journal of Arid Environment,38:397-409 pp.

Bosch, E.H. and Rand, R.S., 2002. Evaluation of Matrix Factorization Method for Data Reduction and Unsupervised Clustering of Hyperspectral Data using Second Order statistics, Aeroscene Conference, Orlando, Florida.

Campbell, J.B., 2002. Introduction to Remote Sensing. Taylor \&Francis, $621 \mathrm{pp}$.

Dregne, H.E. 1991. Desertification Costs: land damage and rehabilitation. In: International Centre for Arid and Semiarid 
Land Studies, Lubbock. X: Texas Tech. University. $31 \mathrm{pp}$.

Eissa, O.K.1980.Semi- Detail Soil Survey and Land Sustainability Classification of El Sahl- Umm

Saga- Elsaragia and Elgedied Schemes. Soil Survey Administration ,Wadmeddani ,Sudan

Elgubshawi, A.A.I.1995. Physical, Chemical and Mineralogical Characteristics of Some Selected Gardud Soils of Kordofan Region: MSc. thesis. Khartoum University.

FAO 1990.Guidelines for soil description. 3rd Edition (revised). FAO, Rome.70pp.

FAO/UNEP 1984. Map of Desertification Hazards: explanatory note. Nairobi, Kenya: United Nations Environment Programme. 14 pp.

Hill, J., Megier, J. \&Mehl, W. 1995a.Land degradation, soil erosion and desertification monitoring in Mediterranean ecosystems. Remote Sensing Reviews, 12(1-2), 107-130.

Huang, C., Townshend, R.G., Zhan, X., Hansen, M., DeFries, R. and Solhberg, R. 1998. Developing the spectral trajectories of major land cover change processes. In: Hyperspectral Remote Sensing and Application ,eds. R.O. Green and Q. Tong. SPIE- The international Society for Optical Engineering, Beijing, pp.288.

Jensen, J.R., 1996. Introductory Digital Image Processing. Englewood Cliffs, PrenticeHall.2ed., New Jersy.

Kennedy-Cooke, B. 1944.The Red Sea Hills. In: Sudan Government Soil Conservation Committee's Report. Khartoum: McCorquodale\& Co. Sudan. 174 pp.

Marcal, A.R.S., Borger, J.S., Bomes, J.A. \&
Costa, P.J.F. 2005.Land cover update by supervised classification of segmented ASTER images. International Journal of Remote Sensing 26.1347-1362pp.

Ministry of Environment Tourism .1996.Towards a National Plan for Environmental Action in the Sudan. Khartoum, Sudan: AOAD. 121 pp.

Pacheco R. and Dawoud, H.A. 1976. Exploratory Soil Survey of North and South Kordofan. Soil Survey Administration, Wadmeddani, Sudan

Pereira, M.D.C.D.S.R. 2004. Land Cover Change Detection in the Limpopo River Basin, Mozambique. MSc. thesis, ITC.The Netherlands.

RSI, 2004.ENVI tutorials. Research Systems Ins.

Salih, E.M. 1996. The Geographical Extent of Desertification in the Sudan. Khartoum, Sudan. Drought and Desertification Control Programmes Coordination and Monitoring Unit.18 pp.

Skidmore, A.K., 2002. Land use and Land cover. Marcel Dekker, Inc., New York.

Tothill, J.D. 1954.Agriculture in the Sudan. London: Oxford University Press. 953 pp.

Tripathy, G. K., Ghosh, T. K. \& Shah, S. D. 1996. Monitoring of desertification process in Karnataka state of India using multi-temporal remote sensing and ancillary information using GIS. International Journal of Remote Sensing, 17(12), 2243-2257pp.

UNEP 1977.World Map of Desertification at scale of 1:25,000,000.A/ CONF 74/2.Prepared by FAO,UNESCO and WMO.

UNEP.2007.Sudan, Post- Conflict Assessment: http: // www. unep .org /sudan/

\section{How to cite this article:}

Elgubshawi A. Abdelmoneim. I., Doka M. A. Elabbas, Suliman Mahgoub and Franz Makechin. 2016. Assessments of the Effect of Land use/ Land Cover Changes on Soil Properties in the North Eastern Nuba Mountains Region, Sudan. Int.J.Curr.Microbiol.App.Sci. 5(3): 692-704. doi: http://dx.doi.org/10.20546/ijcmas.2016.503.082 